\title{
Proteomic identification of cryostress in epididymal spermatozoa
}

\author{
Sung Jae Yoon, Md Saidur Rahman, Woo Sung Kwon, Do Yeal Ryu, Yoo Jin Park and Myung Geol Pang*
}

\begin{abstract}
Background: Cryopreservation of epididymal spermatozoa is important in cases in which it is not possible to collect semen using normal methods, as the sudden death of an animal or a catastrophic injury. However, the freezing and thawing processes cause stress to spermatozoa, including cold shock, osmotic damage, and ice crystal formation, thereby reducing sperm quality. We assessed the motility (\%), motion kinematics, capacitation status, and viability of spermatozoa using computer-assisted sperm analysis and Hoechst 33258/chlortetracycline fluorescence staining. Moreover, we identified proteins associated with cryostress using a proteomic approach and performed western blotting to validate two-dimensional electrophoresis (2-DE) results using two commercial antibodies.

Results: Cryopreservation reduced viability (\%), motility (\%), straight-line velocity (VSL), average path velocity (VAP), amplitude of lateral head displacement (ALH), and capacitated spermatozoa, whereas straightness (STR) and the acrosome reaction increased after cryopreservation $(P<0.05)$. Nine proteins were differentially expressed (two proteins decreased and seven increased) $(>3$ fold, $P<0.05)$ before and after cryopreservation. The proteins differentially expressed following cryopreservation are putatively related to several signaling pathways, including the ephrinR-actin pathway, the ROS metabolism pathway, actin cytoskeleton assembly, actin cytoskeleton regulation, and the guanylate cyclase pathway.

Conclusion: The results of the current study provide information on epididymal sperm proteome dynamics and possible protein markers of cryo-stress during cryopreservation. This information will further the basic understanding of cryopreservation and aid future studies aiming to identify the mechanism of cryostress responses.
\end{abstract}

Keywords: Cryopreservation, Cryostress, Protein, Spermatozoa

\section{Background}

For decades, sperm cryopreservation has been an important tool for assisted reproductive techniques and storing genetic resources $[1,2]$. Using cryopreservation for effective sperm storage has enabled advances in the livestock industry and management of infertility $[3,4]$. However, in cases in which it is not possible to collect spermatozoa normally such as unexpected death and catastrophic injury, cryopreservation of epididymal spermatozoa can be advantageous. Therefore, preservation of epididymal spermatozoa can play an important role in human and animal reproduction.

The freezing and thawing processes of sperm cryopreservation inevitably cause structural and functional alterations, thereby reducing fertility [5-7]. Although the

\footnotetext{
* Correspondence: mgpang@cau.ac.kr

Department of Animal Science \& Technology, Chung-Ang University, Anseong, Gyeonggi-Do 456-756, Republic of Korea
}

bovine is regarded as a model of successful cryopreservation among various species, the process causes up to $50 \%$ loss of viable spermatozoa [8].

During the different stages of cryopreservation, spermatozoa are exposed to various types of stress, such as cold shock, osmotic damage, and ice crystal formation $[7,9]$. Furthermore, cryopreservation induces the excess production of reactive oxygen species (ROS), disruption of mitochondrial membrane potential, and an apoptosislike phenomenon in spermatozoa $[1,10]$. These changes are associated with alterations in sperm membrane compounds, resulting in dramatic reductions in motility, viability, and fertilizing ability [11].

It is well known that sperm functions and structures are affected by protein degradation and post-translational modifications, such as phosphorylation, during cryopreservation $[5,10]$. Research over the past decade has provided compelling evidence that spermatozoa are 
damaged substantially during cryopreservation, thereby reducing sperm function and semen quality $[3,4]$. However, little is known about cryostress at the protein level in spermatozoa. Advances in two-dimensional electrophoresis (2-DE) and mass spectrometry techniques have enabled the identification of proteins related to cryopreservation [12]. Therefore, these methods may facilitate the discovery of biomarkers of cryostress at the proteome level in spermatozoa.

In the present study, bull epididymal sperm cryopreservation was used as a model system of cryopreservation. First, we evaluated various sperm parameters before- and after-cryopreservation. To identify the protein markers related to cryostress, a comprehensive proteomic study of the associated signaling pathways was performed.

\section{Methods}

\section{Sample collection}

Native Korean Bull (Hanwoo) testes were transferred on ice from a local slaughterhouse (Seomun Co., Hwaseong, Korea) to the laboratory within $3 \mathrm{~h}$ [13]. Sperm samples were obtained from nine individual bull epididymides. A small cut was made at the cauda epididymis of the testis and backflushed Phosphate-buffered saline (PBS; SigmaAldrich, St. Louis, MO, USA) into the end of the vas deferens using a $10-\mathrm{mL}$ syringe. Each collected sample was washed by centrifugation at $700 \times g$ for $15 \mathrm{~min}$ [14]. To rule out individual difference in resistance to cryostress, the nine samples were mixed for the sperm parameter and proteome analyses. All procedures were performed according to the guidelines for the ethical treatment of animals by the Institutional Animal Care and Use Committee of Chung-Ang University, Seoul, Korea.

\section{Cryopreservation of spermatozoa}

Sperm cryopreservation was performed as previously described $[15,16]$. Briefly, washed samples were diluted $\left(100 \times 10^{6}\right.$ cells $\left./ \mathrm{mL}\right)$ in Tris-egg yolk buffer (TYB; $250 \mathrm{mmol} / \mathrm{L}$ Tris, $88.5 \mathrm{mmol} / \mathrm{L}$ citric acid, $68.8 \mathrm{mmol} / \mathrm{L}$ glucose, and 20\% egg yolk) and cooled to $4{ }^{\circ} \mathrm{C}$ over $2 \mathrm{~h}$. Then an equal volume of TYB containing $12 \%$ glycerol was added to dilute the sample. After equilibration at $4{ }^{\circ} \mathrm{C}$ for $2 \mathrm{~h}$, samples packaged into $0.5-\mathrm{mL}$ straws were frozen in liquid nitrogen vapor for $15 \mathrm{~min}$. Finally, the straws were plunged into liquid nitrogen for long-term storage. Samples were thawed at $37{ }^{\circ} \mathrm{C}$ for $1 \mathrm{~min}$ after 2 wk of cryopreservation.

\section{Computer-assisted sperm analysis (CASA)}

Sperm motility (\%) and kinematics of the samples were analyzed by the method of Kown et al. using CASA system (Sperm Analysis Imaging System version SAISPLUS 10.1; Medical Supply, Seoul, Korea) [17]. Briefly, $10 \mu \mathrm{L}$ of each sample was observed on $37{ }^{\circ} \mathrm{C}$ Makler chamber (Makler, Haifa, Israel) using the $10 \times$ objective in phase contrast mode. The obtained images were analyzed to assess sperm motility (\%), average path velocity (VAP), straight-line velocity (VSL), curvilinear velocity (VCL), wobble (WOB), straightness (STR), linearity (LIN), and amplitude of lateral head displacement (ALH). At least 250 sperm cells were recorded for each sample.

\section{Assessment of capacitation status by Hoechst 33258 (H33258)/chlortetracycline fluorescence (CTC)}

The H33258/CTC dual staining method was performed as previously described $[16,18]$. Briefly, $15 \mu \mathrm{L}$ of $\mathrm{H} 33258$ solution (10 $\mu \mathrm{g} \mathrm{H33258/mL} \mathrm{PBS)} \mathrm{was} \mathrm{added} \mathrm{to} 135 \mu \mathrm{L}$ of the sample. After a $10 \mathrm{~min}$ incubation at room temperature (RT), $250 \mu \mathrm{L}$ of $2 \%(\mathrm{w} / \mathrm{v})$ polyvinylpyrrolidone (Sigma-Aldrich) in PBS was added to the mixture. Then, the sample was washed by centrifugation at $700 \times g$ for $5 \mathrm{~min}$ and the pellet was resuspended in $150 \mu \mathrm{L}$ of PBS and $150 \mu \mathrm{L}$ of CTC solution $(750 \mathrm{mmol} / \mathrm{L}$ $\mathrm{CTC}$ in $5 \mu \mathrm{L}$ of buffer composed of $20 \mathrm{mmol} / \mathrm{L}$ Tris, $130 \mathrm{mmol} / \mathrm{L} \mathrm{NaCl}$, and $5 \mathrm{mmol} / \mathrm{L}$ cysteine, $\mathrm{pH}$ 7.4).

Capacitation status and viability were analyzed using a Microphot-FXA microscope (Nikon, Tokyo, Japan) under epifluorescent illumination. Four capacitation patterns were observed: live acrosome-reacted (AR), live capacitated (B), live non-capacitated (F), or dead (D). For each sample, at least 400 spermatozoa per slide were evaluated.

\section{DE, gel-image analysis}

All procedures followed the methods of Kwon et al. [17]. Samples were centrifuged at $700 \times g$ for $15 \mathrm{~min}$ with isotonic 45\% Percoll in PBS $[4,17,19]$. After rehydrating with $250 \mu \mathrm{g}$ solubilized protein samples for $12 \mathrm{~h}$ at $4{ }^{\circ} \mathrm{C}, 24-\mathrm{cm}$ long NL Immobiline DryStrips ( $\mathrm{pH} 3-11$; Amersham, Piscataway, NJ, USA) were focused for first-dimension electrophoresis using an IPGphor isoelectric focusing system. After equilibrate the strips, 2-DE was performed using $12.5 \%(\mathrm{w} / \mathrm{v})$ SDS-polyacrylamide gel electrophoresis (SDS-PAGE) gels. Silver staining was performed and the gels were scanned with a GS-800 calibrated scanner (Bio-Rad, Hercules, CA, USA). To detect, quantify, and match spots and to perform the comparative and statistical analyses, PDQuest 8.0 software (Bio-Rad, Hercules, CA, USA) was used.

\section{In-gel digestion}

Proteins were subjected to in-gel trypsin digestion. Excised gel spots were destained with $100 \mu \mathrm{L}$ of destaining solution $(30 \mathrm{mmol} / \mathrm{L}$ potassium ferricyanide, $100 \mathrm{mmol} / \mathrm{L}$ sodium thiosulfate) with shaking for $5 \mathrm{~min}$. After removal of the solution, gel spots were incubated with $200 \mathrm{mmol} / \mathrm{L}$ ammonium bicarbonate for $20 \mathrm{~min}$. The gel pieces were dehydrated with $100 \mu \mathrm{L}$ of acetonitrile and dried in a vacuum centrifuge. The procedure was repeated three times. 
The dried gel pieces were rehydrated with $20 \mu \mathrm{L}$ of $50 \mathrm{mmol} / \mathrm{L}$ ammonium bicarbonate containing $0.2 \mu \mathrm{g}$ modified trypsin (Promega, Madison, WI, USA) for $45 \mathrm{~min}$ on ice. After removing the solution, $70 \mu \mathrm{L}$ of $50 \mathrm{mmol} / \mathrm{L}$ ammonium bicarbonate was added. The digestion was performed overnight at $37{ }^{\circ} \mathrm{C}$. The peptide solution was desalted using a C18 nano column (homemade, Waters Corp., Milford, MA, USA).

\section{Desalting and concentration}

Custom-made chromatographic columns were used for desalting and concentrating the peptide mixture prior to mass spectrometric analysis. A column consisting of 100$300 \mathrm{~nL}$ of Poros Reversed-phase R2 material (20-30- $\mu \mathrm{m}$ beads, PerSeptive Biosystems, Framingham, MA, USA) was packed in a constricted GELoader Tip (Eppendorf, Hamburg, Germany). A 10-mL syringe was used to force liquid through the column by applying gentle air pressure. Thirty microliters of the peptide mixture from the digestion supernatant was diluted with $30 \mu \mathrm{L}$ of $5 \%$ formic acid, loaded onto the column, and washed with $30 \mu \mathrm{L}$ of $5 \%$ formic acid. For analyses by tandem mass spectrometry (MS/ MS) analyses, peptides were eluted with $1.5 \mu \mathrm{L}$ of $50 \%$ methanol/49\% $\mathrm{H}_{2} \mathrm{O} / 1 \%$ formic acid directly into a precoated borosilicate nanoelectrospray needle (EconoTip ${ }^{\mathrm{TM}}$, New Objective, Woburn, MA, USA).

\section{ESI-MS/MS}

MS/MS of peptides generated by in-gel digestion was performed by nano-electrospray ionization (ESI) on a MicroQTOF III mass spectrometer. The source temperature was RT. A potential of $1 \mathrm{kV}$ was applied to the precoated borosilicate nanoelectrospray needles (EconoTip ${ }^{\mathrm{Tm}}$, New Objective) in the ion source combined with a nitrogen back-pressure of $0-5$ psi to produce a stable flow rate (10-30 $\mathrm{nL} / \mathrm{min})$. The cone voltage was $800 \mathrm{~V}$. The quadrupole analyzer was used to select precursor ions for fragmentation in the hexapole collision cell. The collision gas was Ar at a pressure of $6-7 \times 10^{-5}$ mbar and the collision energy was $15-40 \mathrm{~V}$. Product ions were analyzed using an orthogonal time-of-flight (TOF) mass analyzer, fitted with a reflector, a microchannel plate detector, and a time-to-digital converter. The data were processed using a peptide sequence system.

\section{Database search}

An MS/MS ion search was assigned as the ion search option in MASCOT software (MASCOT version 2.3, Matrix Science, Boston, MA, USA). Peptide fragment files were obtained from the peptide peaks in ESI-MS by ESI-MS/MS. Trypsin was selected as the enzyme, with one potentially missed cleavage site. An ESI-QTOF instrument was used for protein mass determination. The peptide fragment files were used to search the database using the Mascot search engine (Matrix Science), and the results were limited to Sus scrofa. Oxidized methionine was set as a variable modification, and carbamidomethylated cysteine was set as a fixed modification. The mass tolerance was set at \pm 1 and $\pm 0.6 \mathrm{Da}$ for the peptides and fragments, respectively. High scores were defined as those above the default significance threshold in MASCOT $(P<0.05$, peptide score $>50)$.

\section{Signaling pathway}

To identify signaling pathways associated with the protein markers, Pathway Studio (v 9.0, Aridane Genomics, Rockville, MD, USA) was used. Differentially expressed proteins were analyzed in Pathway Studio to determine significantly matched pathways for each protein.

\section{Western blotting}

Western blotting was performed as described previously [17], with modifications. Commercial polyclonal antiSOD2 (Abcam, Cambridge, MA, USA) and polyclonal anti-NUDFV2 (Abcam) were used, and monoclonal anti$\alpha$-tubulin (Abcam) was used as a control. Briefly, the samples were washed by centrifugation in DPBS at $10,000 \times g$ for $5 \mathrm{~min}$. The pellets were re-suspended with lysis buffer containing 5\% 2-mercaptoethanol and incubated for $10 \mathrm{~min}$ at RT. The samples were electrophoresed on a $12 \%$ SDS-polyacrylamide gel and transferred to polyvinylidene fluoride membranes (Amersham). The membranes were blocked with PBS-Tween containing $5 \%$ skim milk powder (blocking solution) for $3 \mathrm{~h}$ at RT. After washing, the membranes were incubated overnight with anti-NDUFV2 (1:3,000) and anti-SOD2 (1:5,000) diluted with blocking solution. Then, the membranes were incubated with horseradish peroxidase conjugated antirabbit immunoglobulin G (1:3,000, Abcam) for $1 \mathrm{~h}$. After the membranes were washed, proteins were detected by enhanced chemiluminescence reagents. All bands were scanned with a GS-800 Calibrated Imaging Densitometer (Bio-Rad) and analyzed with Quantity One (v.4.6, Bio-Rad). The signal intensity ratios of the bands were calculated for SOD and NUDFV2/ $\alpha$-tubulin.

\section{Statistical analysis}

Data were analyzed with SPSS v.21.0 (SPSS Inc., Chicago, IL, USA). The Student's two-tailed $t$-test was used to compare the values from before and after cryopreservation after performing normality and variance homogeneity tests. In Pathway Studio, Fisher's Exact Test was used to determine if the pathways were statistically correlated with differentially expressed proteins. $P<0.05$ was considered statistically significant. Data are expressed as the mean \pm SEM. Fisher's exact test was used to determine 
the probability that a protein is involved in a particular signaling pathway $(P<0.05)$.

\section{Results}

Sperm parameters

The motility and motion kinematics of spermatozoa before and after cryopreservation were measured by the CASA technique, as described previously [18]. Motility (\%), VCL, VAP, and ALH significantly decreased during cryopreservation (Figs. 1 and 2, $P<0.05$ ), whereas STR increased significantly (Fig. $2, P<0.05$ ). However, there were no significant differences in VSL, WOB, BCF, or LIN (Fig. 2). To evaluate sperm capacitation status and viability, CTC/H33258 dual staining was performed. The AR pattern increased significantly, whereas the $\mathrm{F}$ pattern significantly decreased during cryopreservation (Fig. 3, $P<0.05)$. However, there was no difference in the $\mathrm{B}$ pattern (Fig. 3). The viability of frozen-thawed spermatozoa was significantly lower than that of spermatozoa before cryopreservation (Fig. 1, $P<0.05$ ).

\section{2-DE}

Spermatozoa samples were analyzed by 2-DE before and after cryopreservation. A total of 285 proteins were detected, and nine proteins were found to be differentially expressed ( $>3$ fold, Table 1 and Fig. 4). The expression of major fibrous sheath protein (AKAP), F1ATPase complexed with aurovertin B (F1-ATPase), triosephosphate isomerase (TPI), nucleoside diphosphate kinase 7 (NDPK7), NADH dehydrogenase flavoprotein 2 (NDUFV2), F-actin-capping protein subunit beta (CAPZB), and superoxide dismutase 2 (SOD2) were higher after cryopreservation. However, expression of outer dense fiber protein 2 (ODF2) and uncharacterized protein LOC616410 were higher in before cryopreservation (Table 1 and Fig. 4).

\section{Western blot}

Western blotting analysis was performed to confirm the 2-DE results. Two differentially expressed proteins were examined using commercial antibodies. SOD2 and NDUFV2 were detected at 25 and $27 \mathrm{kDa}$, respectively. The densities of SOD2 and NDUFV2 expression were higher after cryopreservation than before (Fig. 5 , $P<0.05)$, consistent with the 2-DE results.

\section{Informatics}

Nine proteins were differentially expressed before and after cryopreservation. They were analyzed using Pathway Studio 9. Five signaling pathways were significantly correlated with four proteins (Fig. 6 and Table 2, $P<0.05$ ). CAPZB and ODF2 were correlated with the ephrinR-actin signaling pathway and CAPZB, TPI, and ODF2 were correlated with the Notch pathway (Table $2, P<0.05$ ). The actin cytoskeleton assembly pathway was correlated with CAPZB and actin cytoskeleton regulation was correlated with CAPZB and ODF2 (Table $2, P<0.05$ ). Moreover, the guanylate cyclase pathway was correlated with CAPZB, NDPK, and ODF2 (Table 2, $P<0.05$ ).

\section{Discussion}

Numerous studies have prviously reported that ejaculated and epididymal spermatozoa have differences in sperm maturity, fertility, and sensitivity to freezing. However, in certain situations, it is not possible to collect semen using normal methods, and the cryopreservation of epididymal spermatozoa can be an acceptable alternative. Epididymal spermatozoa can be stored for more than $24 \mathrm{~h}$ without loss of fertility [20]. Moreover, a recent study reported that epididymal spermatozoa had a similar fertilizing-capacity as fresh ejaculated spermatozoa using an in vitro fertilization system [21]. Therefore, the cryopreservation of epididymal sperm can be a useful assisted reproductive technology for the livestock industry and preserving genetic resources. However, the effects of cryo-stress at the proteome level, especially in epididymal spermatozoa, have not yet fully understood.

During cryopreservation, spermatozoa are exposed to various types of stress such as cold shock, osmotic stress, and ice crystal formation $[1,10]$. These environmental changes cause physical and chemical damage to spermatozoa, resulting in changes of various parameters, including
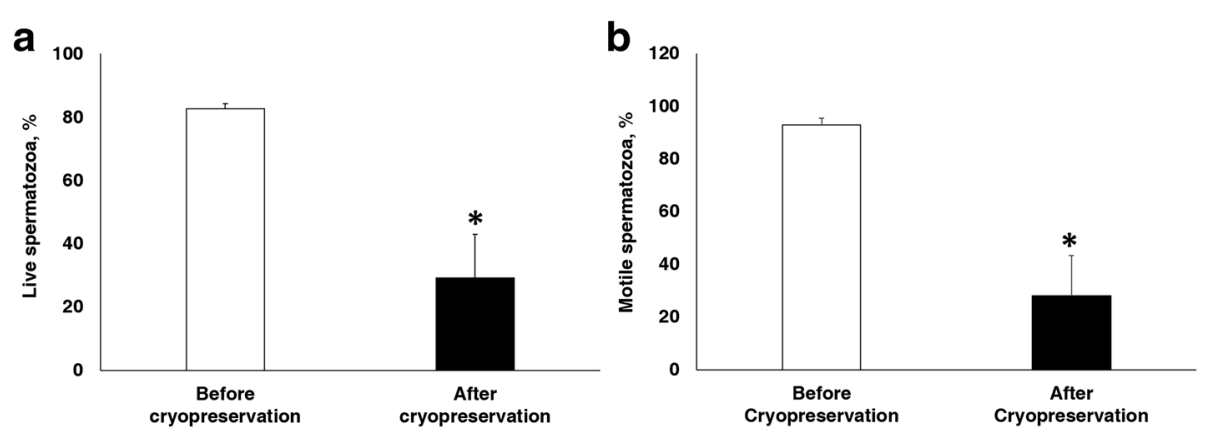

Fig. 1 Effect of cryopreservation on sperm. a Viability b Motility before and after cryopreservation. Data are presented as mean $\pm S E M$. $\left({ }^{*} P<0.05, n=9\right)$ 

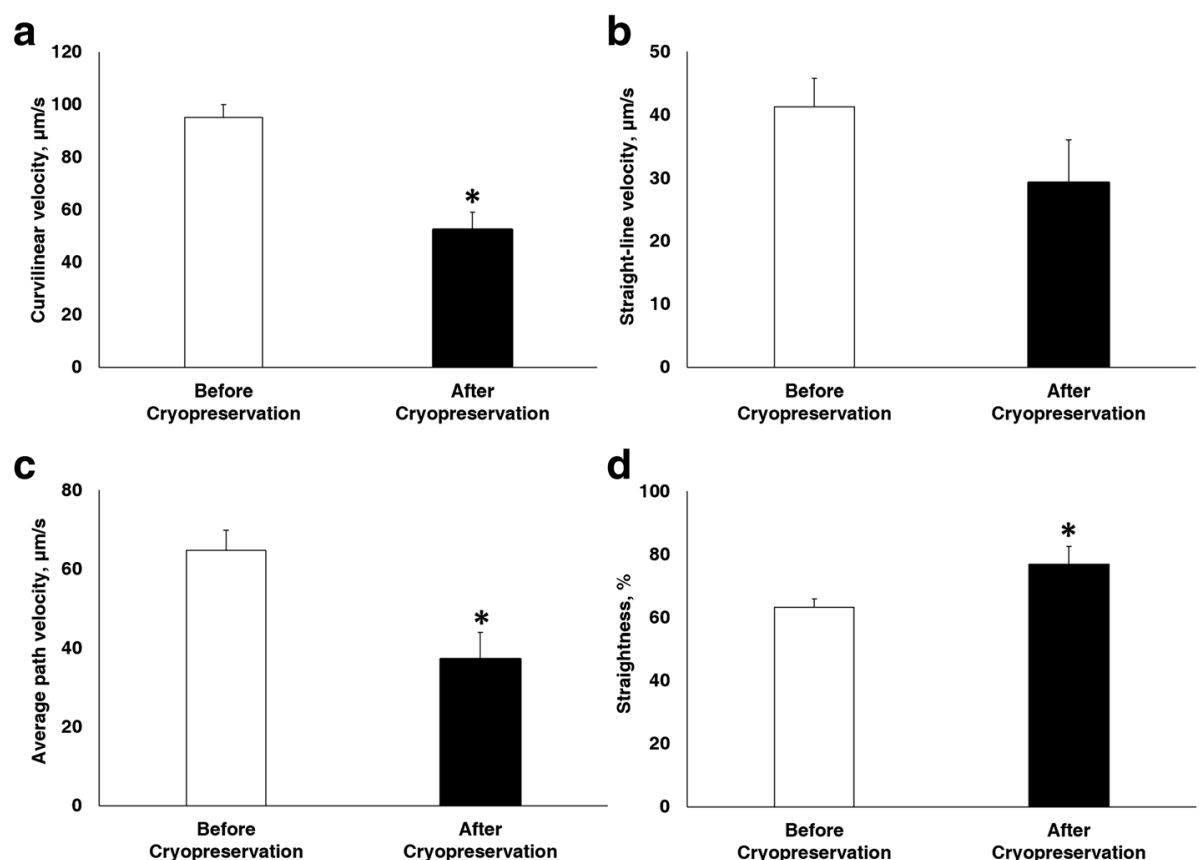

d
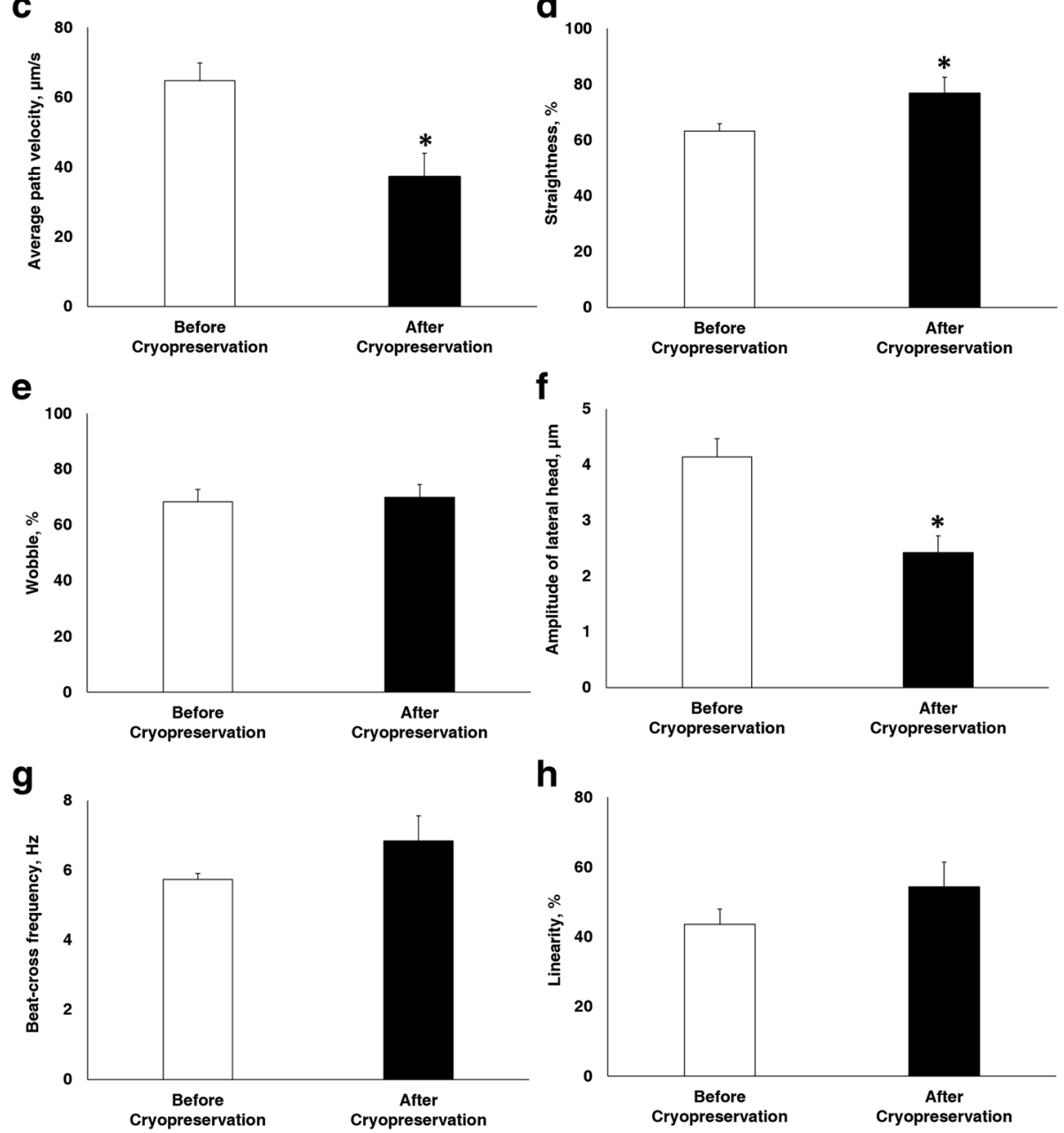

Fig. 2 Effect of cryopreservation on sperm motion kinematics. a Curvilinear velocity $\mathbf{b}$ Straight-line velocity $\mathbf{c}$ Average path velocity $\mathbf{d}$ Straightness e Wobble $\mathbf{f}$ Amplitude of lateral head $\mathbf{g}$ Beat-cross frequency $\mathbf{h}$ Linearity before and after cryopreservation. Data are presented as mean \pm SEM. $\left({ }^{*} P<0.05, n=9\right)$

viability, motility, motion kinematics, and capacitation status [22].

Motility is one of the most important sperm fertility parameters, and numerous studies have described its essential role in sperm transport to the site of fertilization in the female reproductive tract $[12,23]$. Moreover, motion kinematics assessed by CASA provide an accurate representation of sperm movement and its relationship with sperm viability [24]. Our result showed that viability was significantly reduced during cryopreservation. Motility (\%), velocity parameters (VCL, VSL, and VAP), and ALH were also significantly reduced. These parameters are closely related to sperm semen quality and fertility [25]. 

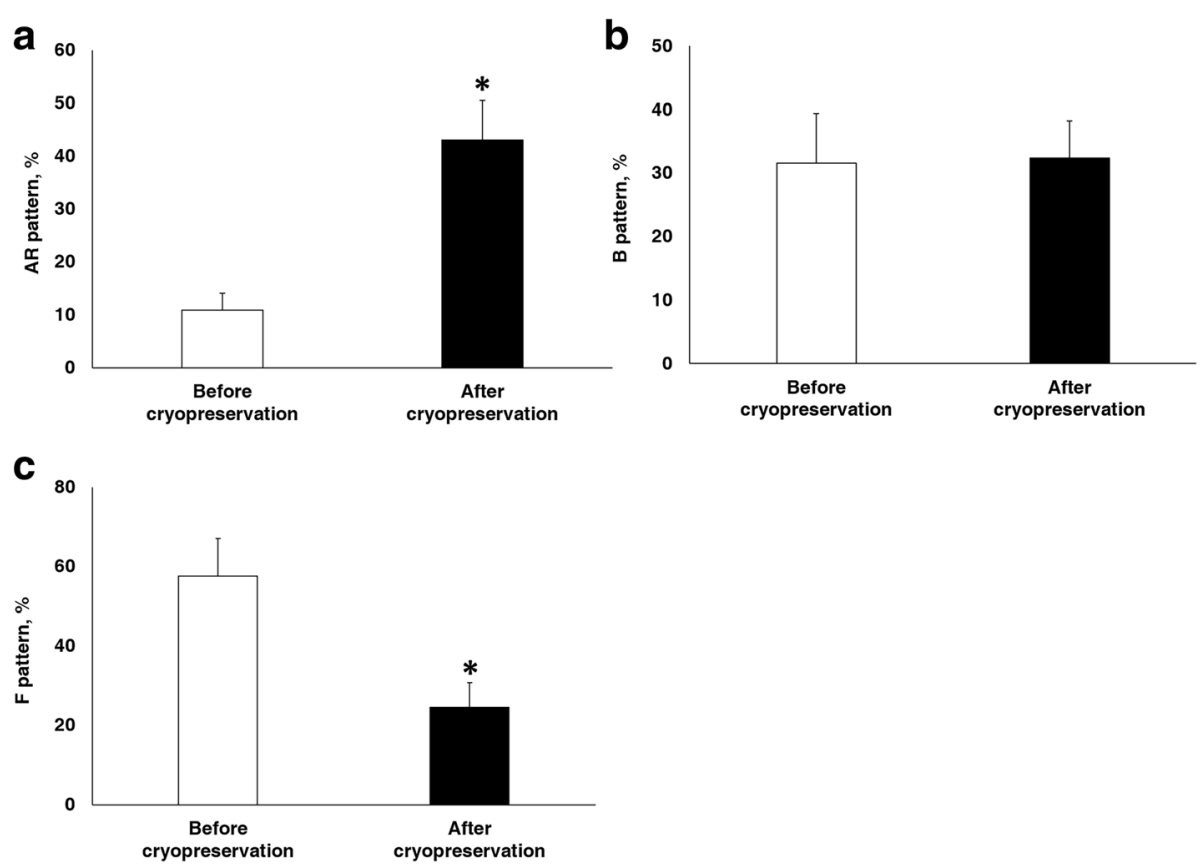

Fig. 3 Effect of cryopreservation on live sperm capacitation status. a AR pattern. b B pattern. c F pattern assessed by combined CTC/H33258 staining. Data are presented as mean \pm SEM. $\left({ }^{*} P<0.05, n=9\right)$

Capacitation refers to the structural and metabolic alterations that allow spermatozoa to fertilize an oocyte $[17,26]$. Without capacitation, spermatozoa lack fertilization ability, although they are motile and morphologically normal [27]. Cryopreservation also results in nonfunctional capacitation, i.e., premature capacitated spermatozoa. Premature capacitation causes an aberrant acrosome reaction in spermatozoa $[5,28]$. In our study, the AR pattern significantly increased and the $\mathrm{F}$ pattern significantly decreased after cryopreservation.

It has been reported that membrane cytoskeletal components are sensitive to temperature and cryoprotectants, which cause damage to sperm surface proteins $[5,10]$. Moreover, cryoprotectant toxicity can induce alterations in sperm membrane components [29]. For these reasons, the mechanisms of cryopreservation and the physiological alterations of spermatozoa should be examined at the protein level using sperm proteomic studies. 2-DE is a typical proteomic technique for purifying individual proteins from various samples [12]. Therefore, we studied the mechanisms of cryostress using the 2-DE technique and confirmed the results using western blotting.

It is generally accepted that transcription, translation, and protein synthesis do not occur in mature

Table 1 Differentially expressed (>3-fold) proteins of spermatozoa at different steps of cryopreservation

\begin{tabular}{|c|c|c|c|c|c|}
\hline Spot no. & Protein & $\mathrm{NCBI}$ no. & MASCOT score ${ }^{a}$ & Expression ratio $^{b}$ & Search \\
\hline 228 & Major fibrous sheath protein chain D, bovine mitochondrial & gi|4588120 & 88.0 & 3.87 & $\mathrm{NCBI}$ \\
\hline 1304 & F1-ATPase complexed with aurovertin B & gi|1827812 & 183.0 & 12.57 & $\mathrm{NCBl}$ \\
\hline 2311 & PREDICTED: Uncharacterized protein LOC616410 & gi|119914715 & 299.0 & 0.25 & $\mathrm{NCBI}$ \\
\hline 4208 & Triosephosphate isomerase & gi|61888856 & 174.0 & 6.48 & $\mathrm{NCBI}$ \\
\hline 4418 & Nucleoside diphosphate kinase 7 & gi|62751773 & 64.0 & 6.13 & SwissProt \\
\hline 4607 & Outer dense fiber protein 2 & gi|84000345 & 290.0 & 0.46 & $\mathrm{NCBI}$ \\
\hline 5204 & NADH dehydrogenase flavoprotein 2 & gi|72004 & 67.0 & 5.30 & SwissProt \\
\hline 5305 & F-actin-capping protein subunit beta & gi|28603770 & 53.0 & 5.73 & $\mathrm{NCBI}$ \\
\hline 7206 & Superoxide dismutase, mitochondrial & gi|88853816 & 74.0 & 3.92 & $\mathrm{NCBI}$ \\
\hline
\end{tabular}

${ }^{a}$ MASCOT scores are $-10 \times \log (P)$, where $P$ is the probability that the observed match is a random event. Individual scores $>40$ indicate identity or extensive homology $(P<0.05)$

${ }^{b}$ Expression ratio is the ratio of relative volume of protein spots with after cryopreservation value to over before 


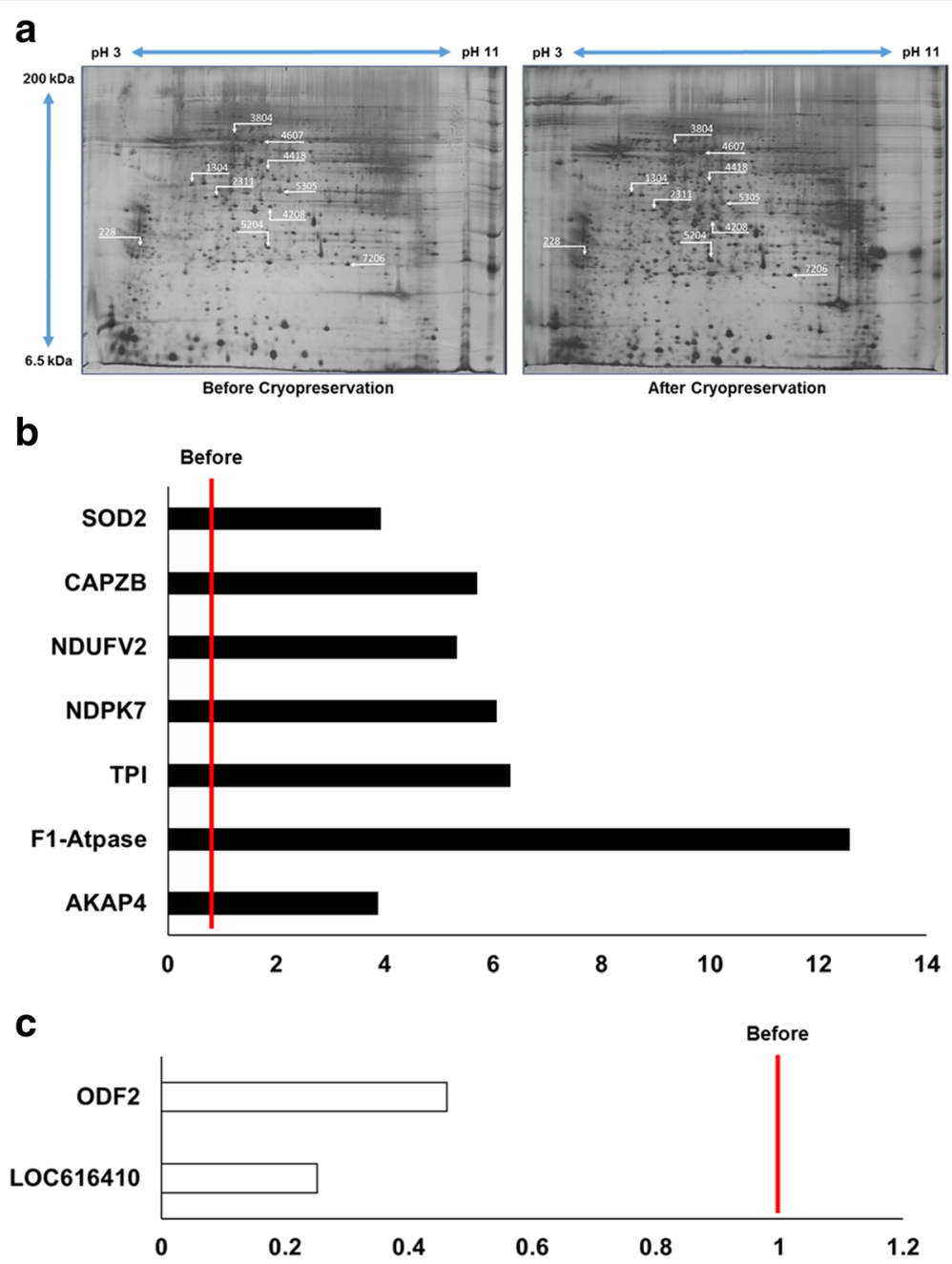

Fig. 4 2-DE Separation of proteins by 2-DE. 2-DE gels were stained with silver nitrate and analyzed using PDQuest 8.0 software. Protein spots from (a) before cryopreservation and after cryopreservation. $\mathbf{b}$ The expression of seven proteins increased significantly after cryopreservation. c The expression of two proteins decreased significantly after cryopreservation. Differentially expressed ( $>3$-fold) proteins were determined by comparing samples before and after cryopreservation $(P<0.05, n=9)$. The line indicates the landmark of equal levels for before cryopreservation

spermatozoa [30, 31]. However, several studies report that mature spermatozoa have the ability to synthesize proteins $[17,32,33]$. These studies suggest that another possible mechanism, such as post translational modifications is involved in cryostress [33]. We found nine proteins that were differentially expressed before and after cryopreservation (Table 1). Among these nine, two proteins (ODF2 and LOC616410) decreased and seven proteins (SOD2, CAPZB, NDUFV2, NDPK, TPI, F1-ATPase, and AKAP) increased after cryopreservation.

ODF2 is a cytoskeletal structure protein localized in sperm flagella [34]. It functions in the maintenance of sperm structures and movement [35]. ODF could be consider as a marker of male infertility factor and defects of ODF can lead to abnormal morphology and infertility [36]. The absence of ODF also could result in nonfunctional tails and affect sperm movement [33]. ODF2 expression decreased after cryopreservation, and as a result, motility and viability were also found to decrease.

SOD2, a member of the superoxide dismutase family, is an isozyme of superoxide dismutase and an antioxidant [37]. SOD2 can improve cell survival by reducing the level of ROS $[38,39]$. In the testis, it reacts with ROS directly and reduces toxicity [40]. During cryopreservation, oxidative stress damages spermatozoa [41]. In our study, SOD2 was extremely highly expressed after cryopreservation. Therefore, it is tempting to speculate that this increased expression reflects a defensive response to protect the spermatozoa against oxidative stress during cryopreservation [42]. 


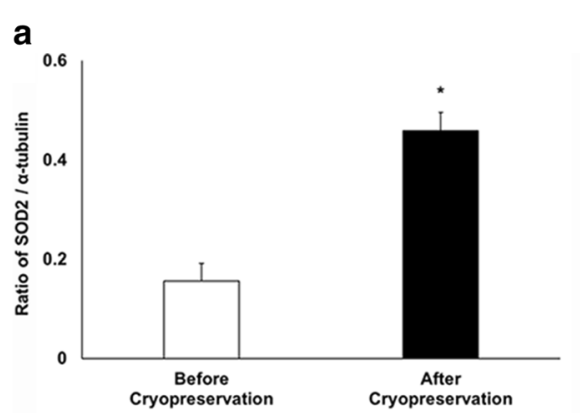

C

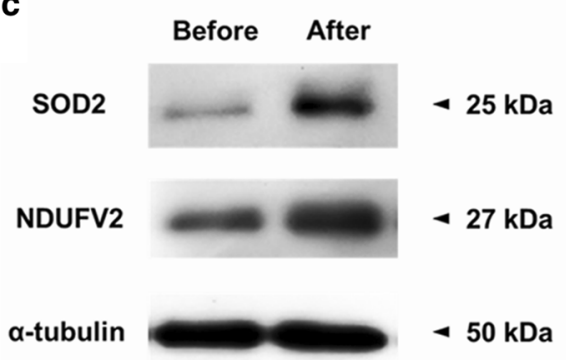

b

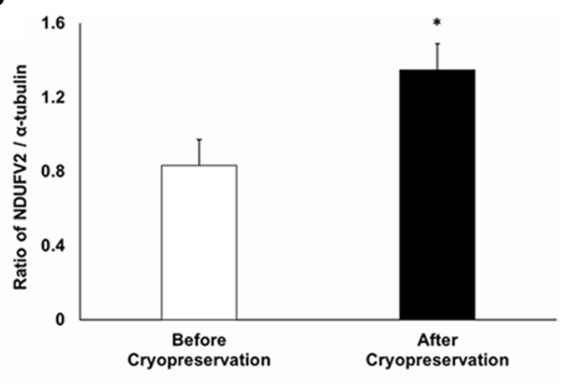

Fig. 5 Expression of SOD and NDUFV2 before and after cryopreservation. a Ratio of SOD2 to a-tubulin expression before and after cryopreservation. b Ratio of NDUFV2 to a-tubulin expression before and after cryopreservation. c Expression of SOD, NDUFV2 and before and a-tubulin after cryopreservation. Data are presented as mean \pm SEM. $\left({ }^{*} P<0.05, n=9\right)$

CAPZB is a member of the F-actin capping protein family and a major cytoskeletal protein [43]. CAPZB is involved in F-actin function. F-actin depolymerization inhibits capacitation and acrosome reactions [44]. Capping proteins assemble and disassemble filaments in the outer acrosomal membrane during capacitation, and these mechanisms are important for the induction of the acrosome reaction [45]. The higher expression of CAPZB after cryopreservation may be related to capacitation-like changes during cryopreservation. Therefore, the capacitation status results from our study suggest that the increase in CAPZB is related to changes in the AR and F patterns.

NDPK localizes in mitochondria and catalyzes reversible reactions involving a nucleoside triphosphate at the expense of ATP [46]. NDPK is also widely known to regulate transcription and cell proliferation as well as energy metabolism [47]. Sperm motility is closely associated with energy metabolism and excessive metabolic activity could reduce the life span of spermatozoa [18]. We believe that it might be associated with the decreased viability and motility in our study (Fig. 1). Moreover, NDPK has protective effects against oxidative stress [48]. Cryostresses such as oxidative stress and cold shock cause metabolic and functional changes in spermatozoa [49]. In our study, NDPK7 increased after cryopreservation (Fig. 4). This suggests that oxidative stress and changes in energy metabolism occur to protect spermatozoa during cryopreservation.

TPI is an enzyme that promotes the conversion of dihydroxyacetone phosphate to D-glyceraldehyde 3-phosphate
[50]. This enzyme plays an important role in sperm metabolism, such as capacitation and the acrosome reaction. Bone et al. [51] have shown that the inhibition of TPI prevents capacitation in rat spermatozoa. The decreased $F$ pattern and increased AR pattern in our capacitation status results might be associated with the high expression of TPI. TPI also induces early capacitation after cryopreservation, resulting in cell death. This protein is highly expressed in spermatozoa that have low motility parameters or poor freezability [52]. In the current study, TPI was highly expressed after cryopreservation (Fig. 4), which may indicate that spermatozoa are damaged during cryopreservation. In addition, our results show that viability and motility decreased (Fig. 1). Moreover, in human sperm, the levels of TPI were higher in asthenozoospermic samples than in normospermic samples [53].

Four of the nine proteins that were differentially expressed before and after cryopreservation were significantly correlated with five signaling pathways (Table 2). These signaling pathways are also associated with sperm functions. The ROS metabolism pathway is associated with SOD2 (Table 2). ROS is necessary for sperm metabolism and various sperm functions such as viability, capacitation and fertility, however high levels of ROS induce oxidative damages to spermatozoa [54]. Oxidative damage causes lower motility, DNA damages, and lipid peroxidation [55]. Membrane phospholipids are related to cell freezability, which affects sperm motility and mitochondrial potential $[16,56]$. SOD2 is a major 
a

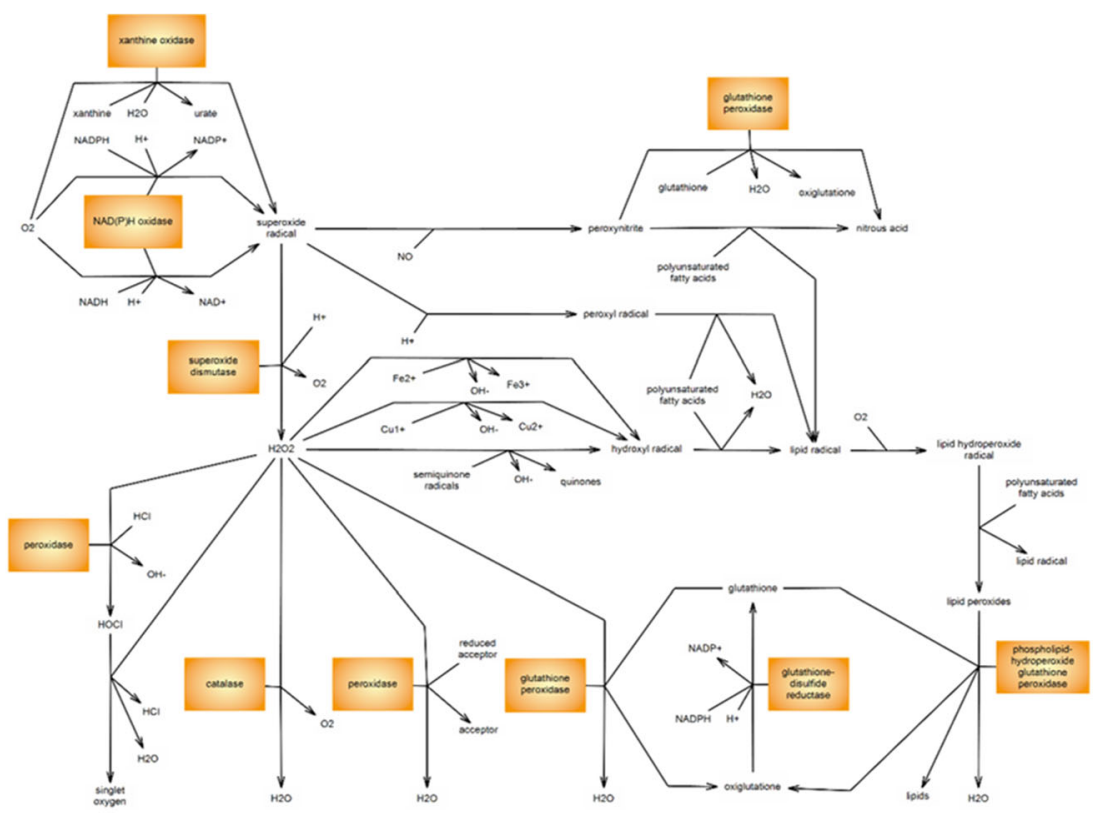

b

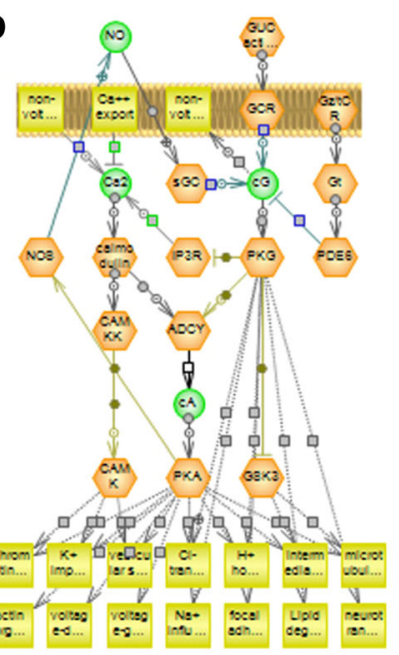

C

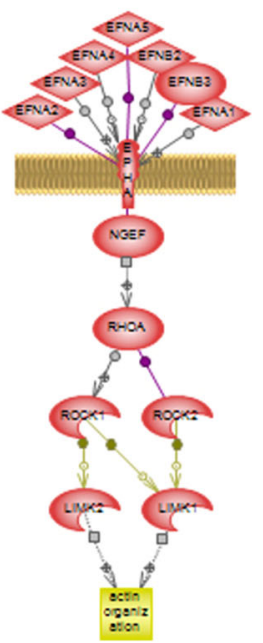

d

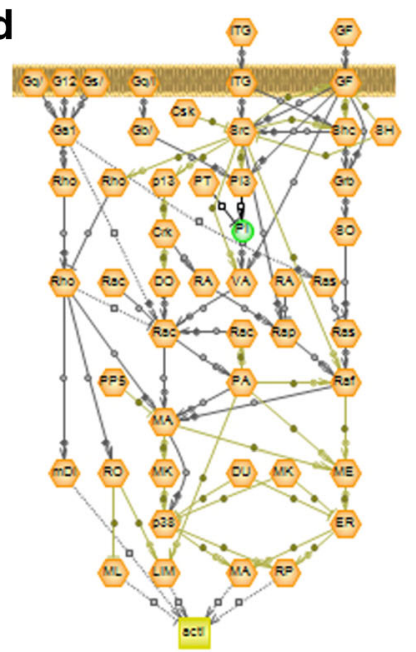

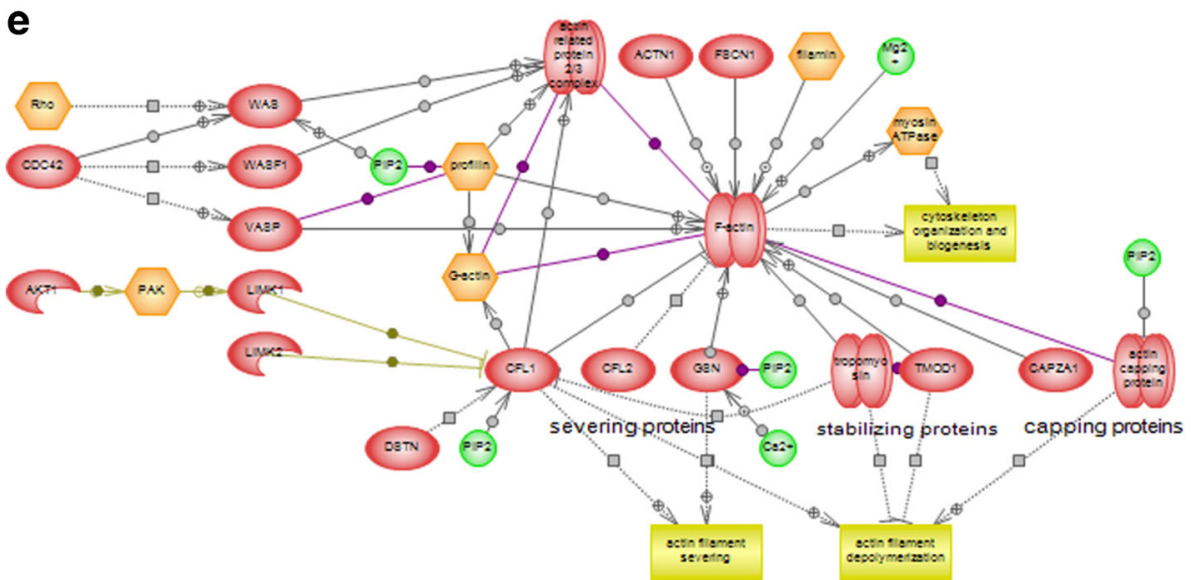

Fig. 6 Signaling pathways associated with differentially expressed proteins as identified by Pathway Studio. a ROS metabolism is associated with SOD2. b Guanylate cyclase pathway is associated with CAPZB, NDPK, and ODF2. c EphrinR-actin signaling pathway is associated with CAPZB and ODF2. $\mathbf{d}$ Actin cytoskeleton regulation associated with CAPZB and ODF2. e Actin cytoskeleton assembly is associated with CAPZB 
Table 2 Signaling pathways associated with differentially expressed proteins as identified by Pathway Studio

\begin{tabular}{lll}
\hline Signaling pathways & Overlapping entities & $P$-value \\
\hline EphrinR - > Actin Signaling & CAPZB, ODF2 & 0.005 \\
ROS metabolism & SOD2 & 0.041 \\
Actin Cytoskeleton Assembly & CAPZB & 0.016 \\
Actin Cytoskeleton Regulation & CAPZB, ODF2 & 0.020 \\
Guanylate Cyclase Pathway & CAPZB, NDPK, ODF2 & 0.034 \\
\hline
\end{tabular}

antioxidant, and it reacts with ROS directly to protect against oxidative stress [40]. ROS metabolism is also related the the guanylate cyclase pathway and energy metabolism [57, 58].

The guanylate cyclase pathway plays an important role in $\mathrm{Ca}^{2+}$ influx and ROS metabolism [58]. The uptake of $\mathrm{Ca}^{2+}$ is a key factor in sperm capacitation and accelerates the acrosome reaction [59]. In the current study, the alterations in capacitation status after cryopreservation may be closely related to this pathway (Fig. 3). Moreover, guanylate cyclase is associated with sperm motility and energy metabolism [60]. Our results show that CAPZB, NDPK, and ODF2 are significantly associated with the guanylate cyclase pathway (Table 2). NDPK has protective effects against oxidative stress and a strong relationship with energy metabolism [47]. The increase in NDPK in our study may have been induced by ROS or excessive energy activity resulting in reduced motility and viability (Fig. 1). Moreover, the increase in SOD2 also can be explained by excessive ROS caused by cryopreservation (Fig. 1, Table 1).

CAPZB was also associated with actin cytoskeleton assembly and actin regulation pathways (Table 2). These pathways are involved in sperm capacitation and the acrosome reaction [61]. Phosphatidylinositol $(4,5)$-bisphosphate and phosphatidylinositol $(3,4,5)$-trisphosphate in these pathways play important roles in the regulation of actin polymerization [62]. Sperm capacitation and the acrosome reaction are closely associated with actin polymerization [63]. F-actin in the actin-related pathways plays a major role in the remodeling of actin structure, the acrosome reaction, and male fertility [64]. It is possible that the significant alterations of capacitation status in our results are related to these pathways (Fig. 3).

\section{Conclusions}

In the present study, we compared sperm parameters and the proteome of bovine epididymal spermatozoa before and after cryopreservation. We identified proteins related to cryostress and their associated signaling pathways. To the best of our knowledge, this is the first study to evaluate the effects of epididymal sperm cryopreservation at the proteome level. Our results indicate that proteins could be useful biomarkers for cryostress, and these biomarkers could be used in future studies to identify the mechanism of cryostress responses.

\begin{abstract}
Abbreviations
2-DE: Two-dimensional electrophoresis; AKAP: Major fibrous sheath protein: ALH: Amplitude of lateral head displacement; AR: Live acrosome-reacted; B: Live capacitated; CAPZB: F-actin-capping protein subunit beta;

CASA: Computer-assisted sperm analysis; CTC: Chlortetracycline fluorescence; D: Dead; ESI: Nano-electrospray ionization; F: Live non-capacitated; F1-ATPase: F1-ATPase complexed with aurovertin B; H33258: Hoechst 33258; LIN: Linearity; MS/MS: Tandem mass spectrometry; NDPK7: Nucleoside diphosphate kinase 7; NDUFV2: NADH dehydrogenase flavoprotein 2; ODF2: Outer dense fiber protein 2; PBS: Phosphate-buffered saline; ROS: Reactive oxygen species; RT: Room temperature; SOD2: Superoxide dismutase 2; STR: Straightness; TOF: Time-offlight; TPI: Triosephosphate isomerase; TYB: Tris-egg yolk buffer; VAP: Verage path velocity; VCL: Curvilinear velocity; VSL: Straight-line velocity; WOB: Wobble
\end{abstract}

\section{Acknowledgments}

This work was carried out with the support of "Cooperative Research Program for Agriculture Science \& Technology Development (Project No. PJ01106101)" Rural Development Administration, Republic of Korea.

\section{Funding}

Funding for this study was provided by "Cooperative Research Program for Agriculture Science \& Technology Development (Project No. PJ01106101)" Rural Development Administration (RDA). RDA had no role in the study design, collection, analysis or interpretation of the data, writing of the manuscript, or the decision to submit the paper for publication.

\section{Availability of data and materials}

The data will not be shared. We provided all data and information on the software, database, and equipment that we used in the present study. In addition, we did not use any new software.

\section{Authors' contributions}

S.J.Y., M.S.R., W.S.K., D.Y.R., and Y.J.P. performed the experiments, analyzed the data, and drafted the manuscript. M.G.P. supervised the design of the study and data analysis and revised the manuscript. All authors critically reviewed the manuscript for intellectual content and gave final approval for the version to be published.

\section{Competing interests}

The authors have declared that there are no conflicts of interests that could be perceived as prejudicing the impartiality of this paper.

\section{Consent for publication}

Not applicable.

\section{Ethics approval and consent to participate}

All procedures were performed according to the guidelines for the ethical treatment of animals by the Institutional Animal Care and Use Committee of Chung-Ang University, Seoul, Korea.

Received: 29 June 2016 Accepted: 1 November 2016

Published online: 21 November 2016

\section{References}

1. Olaciregui M, Gil L, Monton A, Luno V, Jerez RA, Marti J. Cryopreservation of epididymal stallion sperm. Cryobiology. 2014;68(1):91-5.

2. Mota Filho AC, Silva HV, Nunes TG, de Souza MB, de Freitas LA, de Araujo AA, et al. Cryopreservation of canine epididymal sperm using ACP-106c and TRIS. Cryobiology. 2014;69(1):17-21.

3. Celeghini EC, de Arruda RP, de Andrade AF, Nascimento J, Raphael CF, Rodrigues $\mathrm{PH}$. Effects that bovine sperm cryopreservation using two different extenders has on sperm membranes and chromatin. Anim Reprod Sci. 2008;104(2-4):119-31.

4. D'Amours O, Frenette G, Fortier M, Leclerc P, Sullivan R. Proteomic comparison of detergent-extracted sperm proteins from bulls with different fertility indexes. Reproduction. 2010;139(3):545-56.

5. Watson PF. The causes of reduced fertility with cryopreserved semen. Anim Reprod Sci. 2000;60-61:481-92. 
6. Martins M, Justino RC, Sant'anna MC, Trautwein LG, Souza FF. Comparison of two different extenders for cryopreservation of epididymal dog sperm. Reprod Domest Anim. 2012;47 Suppl 6:293-4.

7. Ardon F, Suarez SS. Cryopreservation increases coating of bull sperm by seminal plasma binder of sperm proteins BSP1, BSP3, and BSP5. Reproduction. 2013;146(2):111-7.

8. Park YJ, el Mohamed SA, Oh SA, Yoon SJ, Kwon WS, Kim HR, et al. Sperm penetration assay as an indicator of bull fertility. J Reprod Dev. 2012;58(4):461-6.

9. Castro LS, Hamilton TR, Mendes CM, Nichi M, Barnabe VH, Visintin JA, et al. Sperm cryodamage occurs after rapid freezing phase: flow cytometry approach and antioxidant enzymes activity at different stages of cryopreservation. J Anim Sci Biotechnol. 2016;7:17.

10. Hammerstedt RH, Graham JK, Nolan JP. Cryopreservation of mammalian sperm: what we ask them to survive. J Androl. 1990;11(1):73-88.

11. Zilli L, Beirao J, Schiavone R, Herraez MP, Gnoni A, Vilella S. Comparative proteome analysis of cryopreserved flagella and head plasma membrane proteins from sea bream spermatozoa: effect of antifreeze proteins. PLoS One. 2014;9(6):e99992.

12. Rahman MS, Lee JS, Kwon WS, Pang MG. Sperm proteomics: road to male fertility and contraception. Int J Endocrinol. 2013;2013:360986.

13. Yoon SJ, Rahman MS, Kwon WS, Park YJ, Pang MG. Addition of Cryoprotectant Significantly Alters the Epididymal Sperm Proteome. PLoS One. 2016;11(3):e0152690.

14. Shabanowitz RB, Killian GJ. Two-dimensional electrophoresis of proteins in principal cells, spermatozoa, and fluid associated with the rat epididymis. Biol Reprod. 1987;36(3):753-68

15. Awad MM, Graham JK. A new pellet technique for cryopreserving ram and bull spermatozoa using the cold surface of cattle fat. Anim Reprod Sci. 2004;84(1-2):83-92.

16. Yoon SJ, Kwon WS, Rahman MS, Lee JS, Pang MG. A novel approach to identifying physical markers of cryo-damage in bull spermatozoa. PLoS One. 2015;10(5):e0126232.

17. Kwon WS, Rahman MS, Lee JS, Kim J, Yoon SJ, Park YJ, et al. A comprehensive proteomic approach to identifying capacitation related proteins in boar spermatozoa. BMC Genomics. 2014;15:897.

18. Rahman MS, Kwon WS, Lee JS, Kim J, Yoon SJ, Park YJ, et al. Sodium nitroprusside suppresses male fertility in vitro. Andrology. 2014;2(6):899-909.

19. Rahman MS, Kwon WS, Karmakar PC, Yoon SJ, Ryu BY, Pang MG. Gestational Exposure to Bisphenol-A Affects the Function and Proteome Profile of F1 Spermatozoa in Adult Mice. Environ Health Perspect. 2016.

20. Martins CF, Driessen K, Costa PM, Carvalho-Neto JO, de Sousa RV, Rumpf R, et al. Recovery, cryopreservation and fertilization potential of bovine spermatozoa obtained from epididymides stored at 5 degrees $C$ by different periods of time. Anim Reprod Sci. 2009;116(1-2):50-7.

21. Yang B-C, Kang S-S, Park C-S, Kim U-H, Kim H-C, Jeon G-J, et al. Motility, Fertilizability and Subsequent Embryonic Development of Frozen-thawed Spermatozoa derived from Epididymis in Hanwoo. J Embryo Transf. 2015; 30(4):271-6.

22. Wang AW, Zhang H, Ikemoto I, Anderson DJ, Loughlin KR. Reactive oxygen species generation by seminal cells during cryopreservation. Urology. 1997; 49(6):921-5.

23. Kwon WS, Rahman MS, Pang MG. Diagnosis and prognosis of male infertility in mammal: the focusing of tyrosine phosphorylation and phosphotyrosine proteins. J Proteome Res. 2014;13(11):4505-17.

24. Mostafapor S, Farrokhi Ardebili F. Effects of diluting medium and holding time on sperm motility analysis by CASA in ram. Vet Res Forum. 2014;5(2):101-5.

25. Farrell PB, Presicce GA, Brockett CC, Foote RH. Quantification of bull sperm characteristics measured by computer-assisted sperm analysis (CASA) and the relationship to fertility. Theriogenology. 1998;49(4):871-9.

26. Dona G, Kozuh I, Brunati AM, Andrisani A, Ambrosini G, Bonanni G, et al. Effect of astaxanthin on human sperm capacitation. Mar Drugs. 2013;11(6): 1909-19.

27. Zaneveld $\sqcup$, De Jonge $C J$, Anderson RA, Mack SR. Human sperm capacitation and the acrosome reaction. Hum Reprod. 1991;6(9):1265-74.

28. Cormier N, Sirard MA, Bailey JL. Premature capacitation of bovine spermatozoa is initiated by cryopreservation. J Androl. 1997;18(4):461-8.

29. Ball BA, Vo A. Osmotic tolerance of equine spermatozoa and the effects of soluble cryoprotectants on equine sperm motility, viability, and mitochondrial membrane potential. J Androl. 2001;22(6):1061-9.

30. Aitken RJ, Baker MA. The role of proteomics in understanding sperm cell biology. Int J Androl. 2008;31(3):295-302.
31. Oliva R, de Mateo S, Estanyol JM. Sperm cell proteomics. Proteomics. 2009; 9(4):1004-17.

32. Cheng CY, Chen PR, Chen CJ, Wang SH, Chen CF, Lee YP, et al. Differential protein expression in chicken spermatozoa before and after freezingthawing treatment. Anim Reprod Sci. 2015;152:99-107.

33. Yuan J. Protein degradation and phosphorylation after freeze thawing result in spermatozoon dysfunction. Proteomics. 2014;14(2-3):155-6.

34. Oko R. Comparative analysis of proteins from the fibrous sheath and outer dense fibers of rat spermatozoa. Biol Reprod. 1988;39(1):169-82.

35. Yamaguchi A, Kaneko T, Inai T, lida H. Molecular cloning and subcellular localization of Tektin2-binding protein 1 (Ccdc 172) in rat spermatozoa. J Histochem Cytochem. 2014;62(4):286-97.

36. Petersen C, Fuzesi L, Hoyer-Fender S. Outer dense fibre proteins from human sperm tail: molecular cloning and expression analyses of two cDNA transcripts encoding proteins of approximately 70 kDa. Mol Hum Reprod. 1999;5(7):627-35.

37. Yan L, Liu J, Wu S, Zhang S, Ji G, Gu A. Seminal superoxide dismutase activity and its relationship with semen quality and SOD gene polymorphism. J Assist Reprod Genet. 2014;31(5):549-54

38. Glover M, Hebert VY, Nichols K, Xue SY, Thibeaux TM, Zavecz JA, et al. Overexpression of mitochondrial antioxidant manganese superoxide dismutase (MnSOD) provides protection against AZT- or 3TC-induced endothelial dysfunction. Antiviral Res. 2014;111:136-42.

39. Bernard D, Quatannens B, Begue A, Vandenbunder B, Abbadie C. Antiproliferative and antiapoptotic effects of crel may occur within the same cells via the up-regulation of manganese superoxide dismutase. Cancer Res. 2001;61(6):2656-64

40. Fujii J, luchi Y, Matsuki S, Ishii T. Cooperative function of antioxidant and redox systems against oxidative stress in male reproductive tissues. Asian J Androl. 2003;5(3):231-42.

41. Alapati R, Stout M, Saenz J, Gentry Jr GT, Godke RA, Devireddy RV. Comparison of the permeability properties and post-thaw motility of ejaculated and epididymal bovine spermatozoa. Cryobiology. 2009;59(2):164-70.

42. Cui Y, Zhu H, Zhu Y, Guo X, Huo R, Wang X, et al. Proteomic analysis of testis biopsies in men treated with injectable testosterone undecanoate alone or in combination with oral levonorgestrel as potential male contraceptive. J Proteome Res. 2008;7(9):3984-93.

43. Chen X, Zhu H, Wu C, Han W, Hao H, Zhao X, et al. Identification of differentially expressed proteins between bull $X$ and $Y$ spermatozoa. J Proteomics. 2012;77:59-67.

44. Brener E, Rubinstein S, Cohen G, Shternall K, Rivlin J, Breitbart H. Remodeling of the actin cytoskeleton during mammalian sperm capacitation and acrosome reaction. Biol Reprod. 2003;68(3):837-45.

45. Dvorakova K, Moore HD, Sebkova N, Palecek J. Cytoskeleton localization in the sperm head prior to fertilization. Reproduction. 2005;130(1):61-9.

46. Boissan M, Dabernat S, Peuchant E, Schlattner U, Lascu I, Lacombe ML. The mammalian Nm23/NDPK family: from metastasis control to cilia movement. Mol Cell Biochem. 2009;329(1-2):51-62.

47. Braun S, Mauch C, Boukamp P, Werner S. Novel roles of NM23 proteins in skin homeostasis, repair and disease. Oncogene. 2007;26(4):532-42.

48. Arnaud-Dabernat S, Masse K, Smani M, Peuchant E, Landry M, Bourbon PM, et al. Nm23-M2/NDP kinase B induces endogenous c-myc and $\mathrm{nm} 23-\mathrm{M1}$ /NDP kinase A overexpression in BAF3 cells. Both NDP kinases protect the cells from oxidative stress-induced death. Exp Cell Res. 2004;301(2):293-304.

49. Sorrenti G, Bagnoli A, Miraglia V, Crocetta F, Vitiello V, Ristoratore F, et al. Investigating sperm cryopreservation in a model tunicate, Ciona intestinalis sp. A Cryobiology. 2014:68(1):43-9.

50. Komives EA, Chang LC, Lolis E, Tilton RF, Petsko GA, Knowles JR. Electrophilic catalysis in triosephosphate isomerase: the role of histidine-95. Biochemistry. 1991;30(12):3011-9.

51. Bone W, Jones AR, Morin C, Nieschlag E, Cooper TG. Susceptibility of glycolytic enzyme activity and motility of spermatozoa from rat, mouse, and human to inhibition by proven and putative chlorinated antifertility compounds in vitro. J Androl. 2001;22(3):464-70.

52. Vilagran I, Castillo J, Bonet S, Sancho S, Yeste M, Estanyol JM, et al. Acrosinbinding protein (ACRBP) and triosephosphate isomerase (TPI) are good markers to predict boar sperm freezing capacity. Theriogenology. 2013; 80(5):443-50.

53. Siva AB, Kameshwari DB, Singh V, Pavani K, Sundaram CS, Rangaraj N, et al. Proteomics-based study on asthenozoospermia: differential expression of proteasome alpha complex. Mol Hum Reprod. 2010;16(7):452-62. 
54. Desai NR, Kesari KK, Agarwal A. Pathophysiology of cell phone radiation: oxidative stress and carcinogenesis with focus on male reproductive system. Reprod Biol Endocrinol. 2009;7:114.

55. Koppers AJ, De luliis GN, Finnie JM, McLaughlin EA, Aitken RJ. Significance of mitochondrial reactive oxygen species in the generation of oxidative stress in spermatozoa. J Clin Endocrinol Metab. 2008;93(8):3199-207.

56. Kutluyer F, Kayim M, Ogretmen F, Buyukleblebici S, Tuncer PB. Cryopreservation of rainbow trout Oncorhynchus mykiss spermatozoa: effects of extender supplemented with different antioxidants on sperm motility, velocity and fertility. Cryobiology. 2014;69(3):462-6.

57. Nakamura M, Ikeda M, Suzuki A, Okinaga S, Arai K. Metabolism of round spermatids: gossypol induces uncoupling of respiratory chain and oxidative phosphorylation. Biol Reprod. 1988;39(4):771-8.

58. Jankowska A, Warchol JB. Ca(2+)-modulated membrane guanylate cyclase in the testes. Mol Cell Biochem. 2010;334(1-2):169-79.

59. Kwon WS, Park YJ, el Mohamed SA, Pang MG. Voltage-dependent anion channels are a key factor of male fertility. Fertil Steril. 2013;99(2):354-61.

60. Revelli A, Ghigo D, Moffa F, Massobrio M, Tur-Kaspa I. Guanylate cyclase activity and sperm function. Endocr Rev. 2002;23(4):484-94.

61. Kierszenbaum AL, Rivkin E, Tres LL. Cytoskeletal track selection during cargo transport in spermatids is relevant to male fertility. Spermatogenesis. 2011; 1(3):221-30.

62. Insall RH, Weiner OD. PIP3, PIP2, and cell movement-similar messages, different meanings? Dev Cell. 2001;1(6):743-7.

63. Finkelstein $M$, Megnagi B, Ickowicz D, Breitbart $H$. Regulation of sperm motility by PIP2 (4,5) and actin polymerization. Dev Biol. 2013;381(1):62-72.

64. Lee JS, Kwon WS, Rahman MS, Yoon SJ, Park YJ, Pang MG. Actin-related protein 2/3 complex-based actin polymerization is critical for male fertility. Andrology. 2015;3(5):937-46.

\section{Submit your next manuscript to BioMed Central and we will help you at every step:}

- We accept pre-submission inquiries

- Our selector tool helps you to find the most relevant journal

- We provide round the clock customer support

- Convenient online submission

- Thorough peer review

- Inclusion in PubMed and all major indexing services

- Maximum visibility for your research

Submit your manuscript at www.biomedcentral.com/submit 